\title{
Genetic analysis of ecological relevant morphological variability in Plantago lanceolata L. IV Response and correlated response to bidirectional selection for leaf angle*
}

\author{
Kirsten Wolff and \\ Wilke Van Delden
}

\author{
Department of Genetics, Centre of Biological \\ Sciences, Kerklaan 30, 9751 NN Haren, \\ The Netherlands.
}

Bidirectional selection for leaf angle was imposed for four generations in a population of Plantago lanceolata. A fifth generation was made by intra- and interline crosses. The population originated from an extremely wet hayfield with a high and dense vegetation. A high level of additive genetic variability was indicated by a realized heritability of 0.42 . From the correlated responses realized coheritabilities and genetic correlations were calculated. Several genetic correlations, positive and negative, between leaf angle and other characters were found. The negative correlation of flowering date and leaf angle may retard further evolution of these correlated characters as this is the opposite of what the conditions in this habitat require, namely early flowering plants with a small leaf angle. The fifth generation crosses revealed a substantial directional dominance in the direction of smaller leaf angle.

\section{INTRODUCTION}

Many evolutionary apsects of Plantago lanceolata populations have been studied. Bøcher (1943) and Cavers et al. (1980) have given extensive information on the general biology and ecotypic differentiation of this abundant species. The genetic basis of the ecotypic differentiation in this obligatory outcrossing, windpollinated species was, amongst others, studied by Wolff and Van Delden (1987). By growing plants under uniform conditions, large within and between population components of variability for morphological characters and a distinct ecotypic differentiation was shown. By doing transplant experiments Antonovics and Primack (1982) failed to show genetic differentiation between populations. Van Groenendael (1985a) and Van der Toorn et al. (1984), however, demonstrated genetic differentiation between populations by showing higher survival of the "home" populations. An important factor in bringing about the ecotypic differentiation appeared to be the height of the surrounding vegetation (Van der Toorn and Ten Hove, 1982). High vegetations were positively correlated with erect plants (small leaf angle), and

\footnotetext{
* Grassland Species Research Group Publication No. 144.
}

with long, broad, leaves. In such high and dense vegetations erect plants have higher survival and reproductive success than low, prostrate, plants. Genetic correlations between characters, which are all, in varying degree, important for the fitness of the plant, like leaf angle, number of leaves, leaf and scape length and flowering date were shown to be present (Wolff, 1988).

In view of its apparent predominant role in ecotypic differentiation of $P$. lanceolata in hayfields, leaf angle was subjected to further genetic analysis by means of an artificial selection experiment. The application of artificial selection is an unambiguous way of ascertaining whether additive genetic variability is present for a specific character. Artificial selection is mainly applied in agriculture to improve the yield of crops and livestock. In those cases selection is often applied for economically important characters, as e.g., protein and oil content in maize (Dudley, 1977). In the field there is never selection for a single character, as at the same time selection is also imposed on other, correlated, characters (Lande and Arnold, 1983).

It is to be expected that in natural populations strong directional selection leads to loss of additive genetic variability (Fisher, 1930; Lawrence, 1984). 
High heritabilities for a number of fitness characters can be found in those cases where a negative genetic correlation is present between those characters, as this may prevent further selection (Charlesworth, 1984; Hegmann and Dingle, 1982). Prediction of what will happen to the genetic variability when directional selection acts on one character while stabilizing selection acts on a genetically correlated character is impossible (Mitchell-Olds and Rutledge, 1986). Applying artificial selection to a character provides a more independent determination of response and correlated response to a specified selection regime, than does the determination of genetic variance and covariance with the use of other biometrical designs (Palmer and Dingle, 1986). Correlated responses in a selection experiment may occur when selected genes have direct effects on other characters (pleiotropy), or when the selected genes are in linkage disequilibrium with other genes. The latter situation is most likely not present in the outcrossing species under study. A third cause can be that selection is applied for a character involved in a physiological or developmental system, which is constrained (Bradshaw, 1984).

Leaf orientation in P. lanceolata and its genetic, environmental and physiological control have been studied by Barber et al. (1968). They demonstrated the presence of a considerable genetic diversity in leaf orientation, while the expression of the genes was strongly influenced by light intensity and temperature. Low light levels and high temperatures induced more erect leaves, whereas high light intensities and low temperatures induced prostrate leaves. This was in concordance with a covarying seasonal fluctuation in air temperature and leaf orientation. The importance of leaf shape, size, and pattern of arrangement for solar radiation interception is assessed by Niklas (1988) using computer simulations.

In this study a $P$. lanceolata population from a wet hayfield (Merrevliet) was used for artificial selection for leaf angle. From the results of Wolff and Van Delden (1987) and Van Groenendael $(1985 a)$ it is known that the Merrevliet population consists of individuals which combine the following characteristics: small leaf angle, long and broad leaves, long scapes, high leaf weight and early flowering. Wolff and Van Delden (1987) have studied some genetical aspects of morphological variability. The heritabilities for several characters have been estimated as well as phenotypic and genetic correlations. In the present experiment bidirectional selection for leaf angle was imposed during four generations. Response and correlated response of characters could be determined from regression of the means of characters in the successive generations on the cumulated selection differential. Heritabilities and genetic correlations were calculated and the consequences for natural selection in this population were inferred from the results.

\section{MATERIALS AND METHODS}

\section{Habitat and population description}

Merrevliet (Me) is a wet hayfield, mown once a year in the beginning of July. It is situated in an old, medieval, river-bed, now completely filled in. The vegetation is dense and high. Van Groenendael $(1985 b, 1986)$ has given a full description of the habitat and the demography of $P$. lanceolata in this site. Life history traits were found to be important for population growth rate. Survival and plant size seemed to be important demographic characteristics in this stable habitat, where competition for light is most likely a major biotic control mechanism (Van Groenendael, 1985a, $b$ ).

\section{General experimental design}

Seeds were germinated in petri dishes with wet filter paper and the resulting seedlings were grown in pots in the greenhouse under continuous additional light for 16 hours per day. Leaf angle was determined as the angle, in degrees, of two leaves which are more or less opposite of each other in the rosette. For this purpose the third and the fourth leaves, counted from the youngest on, at the eight leaf stage of the plant were used. High values (maximum 180 degrees) correspond to prostrate leaves and low values to erect leaves.

It was known that the season influenced the expression of the character leaf angle strongly. It was therefore decided that in each seed generation the seeds were divided into two groups. One group was germinated and the resulting plants were scored for leaf angle. The extreme plants of this lot were used as parents for the next generation as described below. The selection differentials were determined from this sample. The second sample was stored at $4^{\circ} \mathrm{C}$ and the samples of each of the four generations were germinated simultaneously and measured for many characters in a final experiment. From this sample the selection responses were calculated. 


\section{Selection procedure}

As the base (B) population 195 plants were used. From the base population 20 plants were selected with a small leaf angle (low line: L), 20 plants with a large leaf angle (high line, $\mathrm{H}$ ) and 20 plants with values around the median (median line, M). In each of the three lines the plants were crossed pairwise, at random, leading to ten full-sib families per line, crosses were made reciprocally. In the next generations only the $\mathrm{H}$ and $\mathrm{L}$ lines were continued. In each line and in each generation 200 plants were grown, 20 plants from each full-sib family, ten from each reciprocal cross. In each generation the 20 plants with the highest $(\mathrm{H})$ or the lowest (L) values were selected and again crossed pairwise. Four selection cycles were carried out over a three year period, leading to four generations per line coded $\mathrm{H} 1$ to $\mathrm{H} 4$ and $\mathrm{L} 1$ to $\mathrm{L} 4$ (fig. 1).

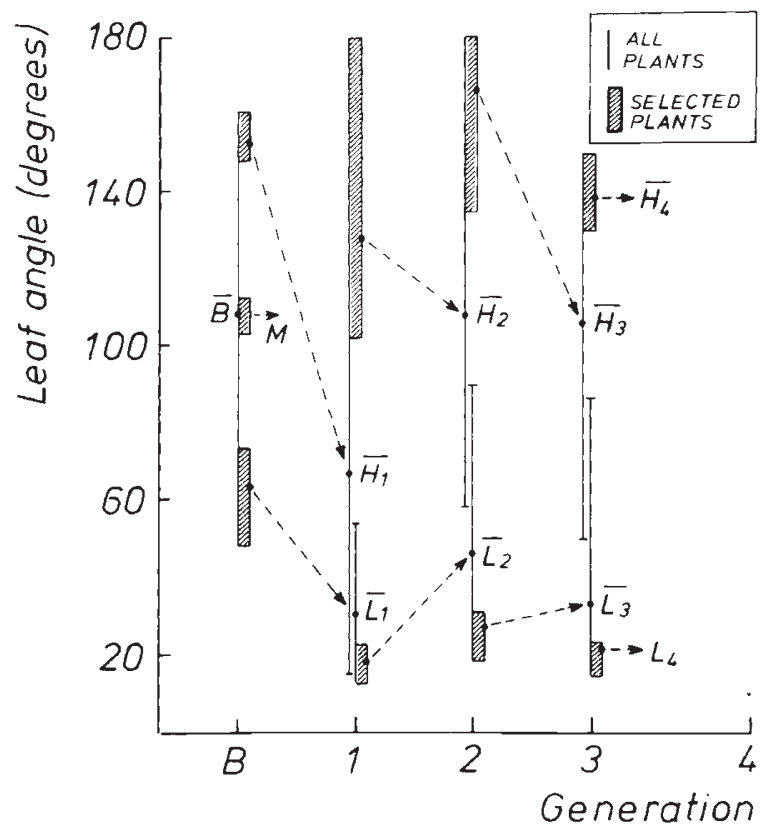

Figure 1 Scheme of the selection procedure, indicating mean of leaf angle of the groups and the means of the selected plants with their range, measured at the moment of selection.

\section{Final experiment 1}

A final experiment was carried out to obtain a simultaneous comparison of successive generations and to measure other characters at the same time. In this experiment, plants grown from seeds derived from all four generations were grown simultaneously in a randomized design during summer. Altogether 390 plants were grown: four plants (not reciprocal) from each full-sib family, for each generation, as well as 30 plants from the base population.

Both cotyledon length and leaf angle were determined. Flowering date was recorded as the day after germination on which the first stamens were visible. After 11 weeks the plants were harvested and length of the longest leaf of all plants was measured. Number of rosettes, number of leaves, width of the widest leaf, number of scapes, length of the longest scape and spike belonging to this scape were determined in only five out of ten families. The above ground biomass was separated into leaf material (leaf weight) and in scapes and spikes (generative weight). For weight determination the material was dried at $80^{\circ} \mathrm{C}$ for several days. The weights of leaves, generative organs (all generations) and roots ( $\mathrm{H} 2, \mathrm{H} 4, \mathrm{~L} 2, \mathrm{~L} 4$ only) were determined. From these data leaf length/width ratio, reproductive effort (expressed as the ratio generative weight/generative weight + leaf weight) and shoot/root ratio were calculated.

\section{Final experiment 2}

In a second experiment plants from the L4 and $\mathrm{H} 4$ generations were used to make some additional crosses. Crosses were made within the two lines (indicated by $\mathrm{L} 4 \mathrm{~L} 4$ and $\mathrm{H} 4 \mathrm{H} 4$ ), two pairwise matings per intra-line combination, and crosses were made between the lines (reciprocally, indicated by L4H4 and H4L4), three matings per inter-line combination. Six plants from each cross were grown in an experiment during autumn (a total of 60 plants). Leaf angle, number of leaves and length of the fourth leaf were determined 45 days after germination. Eight days later the length of the longest leaf, leaf weight and root weight were determined as described above.

\section{Calculation of heritabilities, coheritabilities and genetic correlations}

Realized heritabilities were calculated as $h^{2}=$ $R_{\mathrm{x}} / S_{\mathrm{x}}$, as the variances did not differ in the four generations. $R_{\mathrm{x}}$ is the selection response and $S_{\mathrm{x}}$ is the selection differential of leaf angle.

As there were no differences between the responses in the $\mathrm{L}$ and $\mathrm{H}$ line, the heritability estimates were based on the divergence between the $\mathrm{H}$ and $\mathrm{L}$ lines. The realized heritability was calculated as the regression of generation means on the cumulated selection differential (Hill, 1972; Falconer, 1981). The regression line was forced to 
go through the origin, as at generation $0 R$ and $S$ are both equal to 0 . The cumulated selection differential was not corrected before regression of the cumulated response on the cumulated selection differential as $\sigma_{\mathrm{P}}$ was not different for leaf angle during selection and the final experiment $(27 \cdot 1$ and 24.5 respectively). The standard error (s.e.) of the heritability is taken as the s.e. of the regression, which may, however, be an underestimation (Hill, 1972).

The coheritability is equal to $h_{\mathrm{x}} h_{\mathrm{y}} r_{\mathrm{A}}$, in which $h_{\mathrm{x}}$ and $h_{\mathrm{y}}$ are the square roots of the heritabilities of the characters $\mathrm{x}$ and $\mathrm{y}$ respectively, and $r_{\mathrm{A}}$ is the genetic correlation between both characters. Realized coheritabilities were calculated as

$$
\operatorname{coh}_{(\mathrm{x}, \mathrm{y})}^{2}=\frac{C R_{\mathrm{y}}}{S_{\mathrm{x}}} \frac{\sigma_{\mathrm{P}(\mathrm{x})}}{\sigma_{\mathrm{P}(\mathrm{y})}} .
$$

$C R_{\mathrm{y}} / S_{\mathrm{x}}$ was estimated as the regression of the cumulated response on the cumulated selection differential. $\sigma_{\mathrm{P}(\mathrm{x})}$ and $\sigma_{\mathrm{P}(\mathrm{y})}$ are the means of the phenotypic standard deviation of the four generations and the original population (B) of the characters $\mathrm{x}$ and $\mathrm{y}$ respectively. The genetic correlation $r_{\mathrm{A}}$ was calculated as

$$
r_{\mathrm{A}(\mathrm{x}, \mathrm{y})}=\operatorname{coh}_{(\mathrm{x}, \mathrm{y})}^{2} / \sqrt{h_{\mathrm{x}}^{2} * h_{\mathrm{y}}^{2}} .
$$

The heritabilities of the characters, other than leaf angle, were derived from an earlier experiment, in which biparental families were used (Wolff and Van Delden, 1987).
The s.e. of the genetic correlations were estimated following Falconer (1981):

$$
\sigma_{(\mathrm{rA})}=\frac{1-r_{\mathrm{A}}^{2}}{\sqrt{2}} \sqrt{\left[\frac{\sigma_{(h 2 \mathrm{x})} \sigma_{(h 2 \mathrm{y})}}{h_{\mathrm{x}}^{2} h_{\mathrm{y}}^{2}}\right]},
$$

where $\sigma$ denotes standard error. As $\sigma_{(h 2 y)}$ is derived from full sib correlation it is estimated as the square root of $16 h_{y}^{2} / T$, in which $T$ is the number of plants used in the experiment (Falconer, 1981).

\section{RESULTS}

For the selected character, leaf angle, a strong response was obtained (table 1, fig. 2). From the selection response and the cumulative selection differential a realized heritability of 0.425 (with a s.e. of 0.044 and a significance of 0.0006 ) was calculated for leaf angle. In later generations the response of leaf angle to further selection seemed to be somewhat smaller than in the first generation.

Means for the characters not selected for were calculated (table 1). In fig. 2 the response of leaf angle and the correlated response of five other characters are plotted against the cumulated selection differential of leaf angle. For some characters a strong correlated response was found, for others it was less pronounced. Using the same material in a parallel experiment, with different light conditions, the same trend was present (data not given). Table 2 shows the coheritabilities calculated from

Table I Means of morphological characteristics in the different generations of the two lines selected for leaf angle, the base population (B) and the median line (M) in the final experiment, between brackets the number of plants on which each mean was based

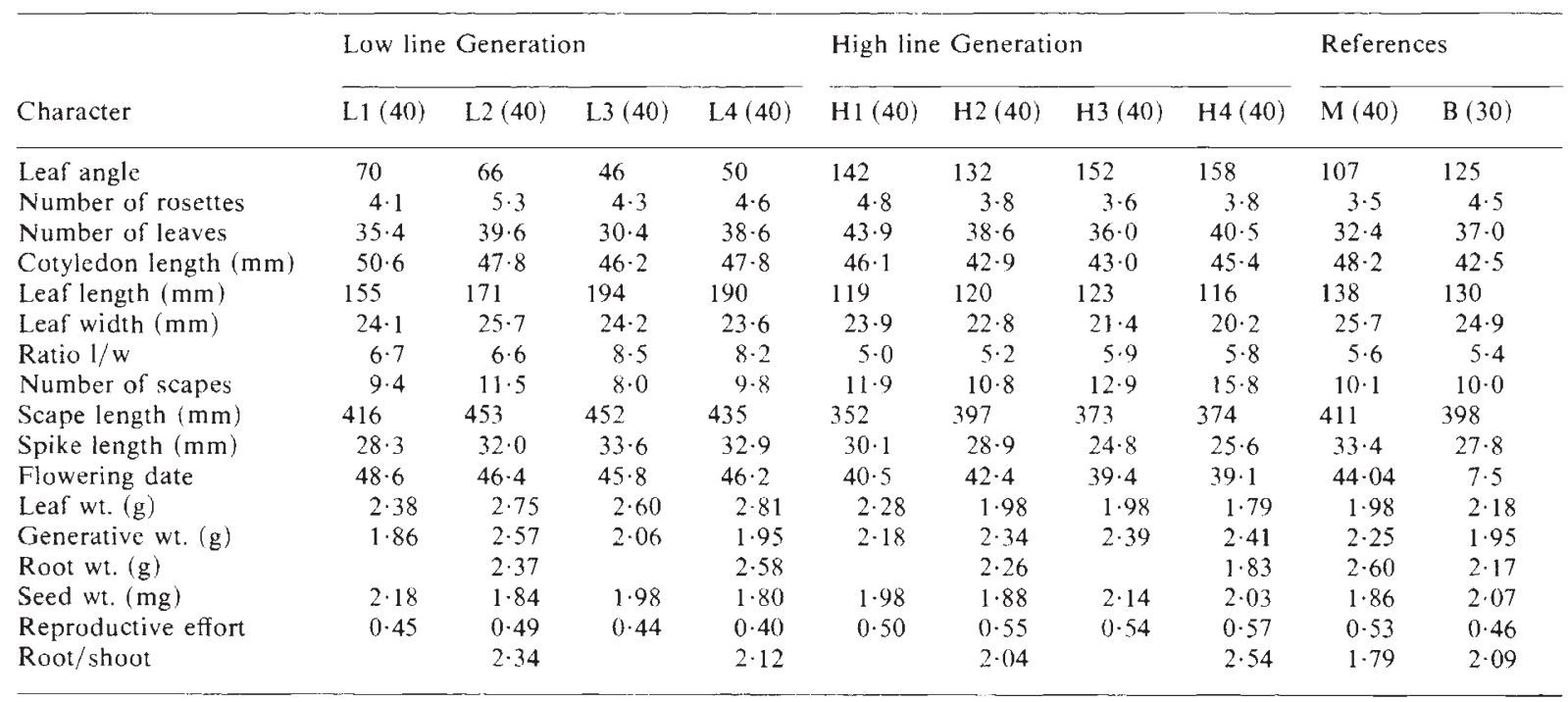



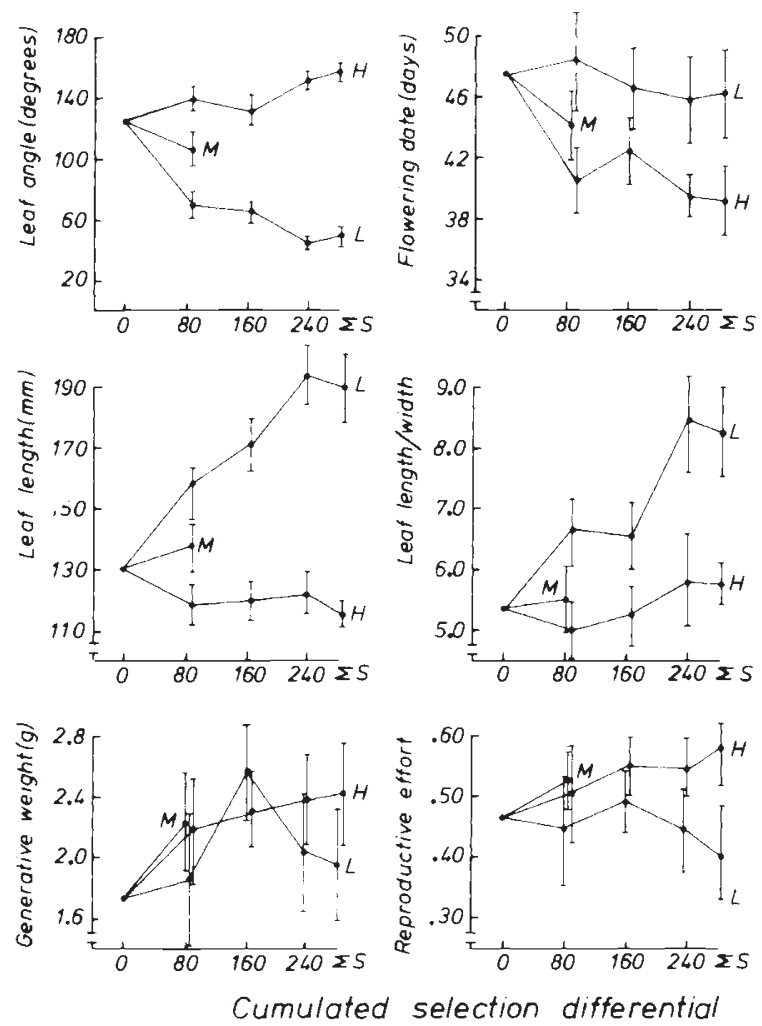

Figure 2 Response and correlated response of several characters over four generations of selection for leaf angle. Means (given with their $95 \%$ confidence intervals) are plotted against the cumulative selection differential of leaf angle. See text for further explication of selection procedures. the regression as described in Materials and Methods. Coheritabilities are not given for those characters for which a regression with $P$ larger than 0.20 was present. Positive coheritabilities were present for leaf angle with number of scapes and reproductive effort, whereas cotyledon length, leaf length, leaf width, leaf length/width ratio, scape length, spike length, flowering date and leaf weight had negative coheritabilities with leaf angle (significance of regression $P<0.05$ ).

Genetic correlations were calculated using the heritability for leaf angle calculated from the present experiment, as this is probably the best estimate and for the other characters the heritability estimates were used from Wolff and Van Delden (1987) (table 2). Positive correlations indicate that leaf angle (large leaf angle $=$ prostrate leaves) is positively correlated with a high value of the other character, e.g., with number of scapes. A negative correlation as in the case of leaf angle and flowering date, means an association of late flowering with a small leaf angle. Thus positive or negative correlations are not equivalent to "favourable" and "unfavourable" associations of characters, respectively. In this respect "favourable" associations are considered as those combinations of characters which are generally found and which are supposed to give rise to higher fitness. Most of the genetic correlations were in the expected direction, e.g., erect leaves with long leaves and high leaf weight. One strong "unfavourable" association appeared to be present, namely erect leaves with late flower-

Table 2 Realized coheritabilities $\left(c o h^{2}\right)$ and genetic correlations $\left(r_{\mathrm{A}}\right)$ between leaf angle and other morphological characters in the $\mathrm{H}$ and the $\mathrm{L}$ line, as calculated from correlated responses together with the sign of the expected correlations as inferred from results of Van Groenendael (see text). The significance and s.e. of the regression of the correlated response on the cumulative selection differential and of the genetic correlation $r_{\mathrm{A}}$ is given (-: no value given because significance of regression is $P>0.05$ )

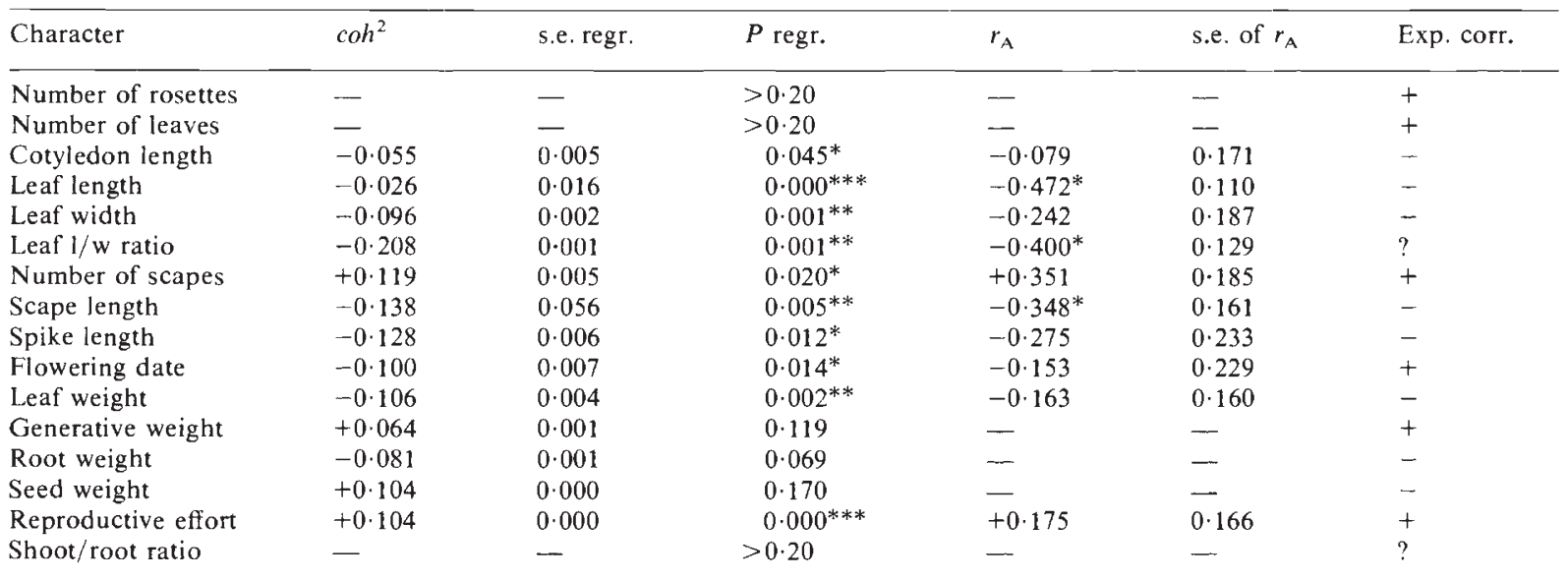

${ }^{*} P<0.05 . * * P<0.01 .{ }^{* * *} P<0.001$. 
ing. Genetic correlations always have very large confidence intervals; the correlation of leaf angle with leaf length, leaf length/width ratio and scape length are significantly different from 0 (table 2).

Results from the second experiment, involving matings within and between the lines in generation four, are given in table 3 . The means in this experiment, conducted in autumn, differed from the means of the first experiment, conducted in summer due to seasonal influences. In the second experiment large differences were found between the $\mathrm{H} 4 \mathrm{H} 4$ and L4L4 matings $\left(\mathrm{P}_{1}\right.$ and $\mathrm{P}_{2}$, respectively) for most of the characters. The interline matings $\left(F_{1}\right)$ gave values between both extremes. The presence of heterosis was measured as $F_{1}-\bar{P}$ and was tested with a $t$-test, with $H_{0}: \mathrm{F}_{1}-\overline{\mathrm{P}}=0$. Heterosis, as found here, is proof of directional dominance, and is a measure of the average dominance of the alleles at the loci involved in determining the character under study. Fairly large heterosis effects were present, alleles from the L-line were on the average dominant for leaf angle, length of the fourth leaf and alleles from the $\mathrm{H}$-line were on the average dominant for leaf and root weight, although the heterosis was only significant for leaf angle. The LH and HL matings were not significantly different from each other for any of the characters measured, though for leaf and root weight maternal effects seemed to be present.

\section{DISCUSSION}

Population differentiation in $P$. lanceolata is strongly associated with vegetation height and leaf angle seems to be an important adaptive character. Therefore studying leaf angle in an artificial selection experiment will provide information about the additive genetic variance for this character and thus about the potential for selection. The rapid divergence in leaf angle of the $\mathrm{H}$ and $\mathrm{L}$ line is striking. The presence of a considerable level of additive genetic variability for leaf angle has thus been shown. It also indicates that the number of genes involved with a major effect is small. This is in concordance with results from a gene localisation experiment in which quantitative trait loci were localised with the aid of allozyme markers (Wolff, 1987).

In addition to a high level of additive genetic variability for leaf angle, a significant dominance effect is also present. The observed direction of dominance, i.e., in the direction of small leaf angle, is in the direction of the phenotype favoured by natural selection in this population where selection has been for reduced leaf angle. In the light of the hypothesis that dominance may be solely the consequence of biochemical pathways (Kacser and Burns, 1981) it is interesting to know which dominance relationships will be found in a selection experiment with a grazed pasture population, where natural selection for a large leaf angle occurs.

In studying the evolution of correlated characters, correlations should be expressed in genetic correlations and not in phenotypic correlations, as the latter do not have evolutionary consequences (Charlesworth, 1984). The absence of close correspondence of phenotypic and genetic correlations can for instance be caused by the positive effect of beneficial environmental conditions which obscure genetic correlations. Consequently geneenvironment interactions are not only important in the evolution of a single character but also in the evolution of related characters (Palmer and Dingle, 1986). This means that correlations found in a selection experiment may be different from those in the field: environmental constraints, e.g., low nutrient levels, may bring about changes in the nature of constraints (Law, 1979; Silander, 1985). Besides, taking into account genetic as well as environmental constraints, the role of plasticity

Table 3 Means of characters measured in intra- and interline matings, and heterosis effects $\left(F_{1}-\bar{P}\right)$ expressed as absolute value and as percentages of $\bar{P}$. The significance of $F_{1}-\bar{P} \neq 0$ is given (see text, ${ }^{* * *} P<0.001$ )

\begin{tabular}{|c|c|c|c|c|c|c|}
\hline \multirow[b]{2}{*}{ Character } & \multicolumn{4}{|l|}{ Mating } & \multirow[b]{2}{*}{$F_{1}-\bar{P}$} & \multirow[b]{2}{*}{$\left(F_{1}-\bar{P}\right) / \bar{P}$} \\
\hline & L.L & $\mathrm{HH}$ & $\mathrm{LH}$ & $\mathrm{HL}$ & & \\
\hline Number of leaves & $5 \cdot 8$ & $7 \cdot 3$ & $6 \cdot 5$ & $6 \cdot 9$ & $+0 \cdot 15$ & +2 \\
\hline Fourth leaf length $(\mathrm{mm})$ & 131 & 109 & 123 & 129 & +6 & +5 \\
\hline Leaf length $(\mathrm{mm})$ & 180 & 136 & 156 & 154 & -3 & -2 \\
\hline Shoot/root & $2 \cdot 84$ & $2 \cdot 20$ & $2 \cdot 51$ & $2 \cdot 66$ & +0.07 & +3 \\
\hline
\end{tabular}


in plants can be of great importance (Cheverud, 1984; Schlichting 1986; Schaal and Leverich, 1987).

Genetic correlations of characters may be of physiological origin, e.g., via plant hormones (size measures) or caused by limited availability of nutrients or assimilates. Niklas (1988) discussed in a theoretical study the evolutionary importance of the phyllotactic pattern of a plant, of which leaf angle is an important component. The phyllotactic pattern is important as e.g., a smaller leaf angle means a lower light interception in a sparse vegetation and this may mean a lower assimilation rate. In this way a change in the phyllotactic complex of a species may necessitate compensatory changes in features not directly under control of the complex, e.g., in flowering date or growth rate (Niklas, 1988). In this study a limitation by low assimilation rate in the L-line does not seem to be present as the total biomass produced in both lines is about equal.

Many of the correlations found here seem to have a physiological origin or are caused by a developmental constraint. Especially plant hormones seem to be good candidates to be held responsible for the correlation of leaf angle and leaf length, mediated by the intensity of light intercepted. Barber et al. (1968) showed that plant hormones were involved in the determination of leaf angle; probably gibberellin blocked the expression of the genes for prostrate leaf orientation. The observed selection response and the genetic correlations may not be generally valid for other populations or for the species as a whole, as often differences in genetic correlations between populations are found (Silander, 1985; MitchellOlds and Rutledge, 1986). However, some of the strong correlations, e.g., leaf angle and leaf length, seem clearly physiologically determined and may thus also hold for other populations. The presence of uniform correlations over populations in this species was found in a diallel analysis, involving two contrasting populations (Wolff, 1988). In this respect a comparison with a selection experiment on a population from a grazed pasture for the presence and sign of genetic correlations would be interesting. Investigations into the physiological differences between the lines may indicate whether these characters have general physiological correlates.

Heritabilities for characters related to fitness often appear to be low (Bradshaw, 1984). However, high heritabilities are expected in those cases where a negative genetic correlation exists between two fitness characters. In some cases the presence of negative genetic correlations has been demonstrated (Silander, 1985; Mitchell-Olds and Rutledge, 1986). In Impatiens capensis, however, positive genetic correlations between fitness components were shown (Mitchell-Olds, 1986). Many "favourable" associations of characters were revealed in this study. As both early flowering and a small leaf angle seem to be important in this population (an early mown hayfield) the "unfavourable" association of small leaf angle and late flowering may, at least partly, be the reason why further evolution is retarded and additive genetic variability is maintained. The mean leaf angle in the present study is 125 degrees, measured under artificial conditions in the greenhouse. This value will be different under natural conditions, where a stronger competition for light exists. The leaf angle of the population may be an intrinsic optimum in its original habitat. However, in view of the genetic correlations, it is more probable that the leaf angle found is an optimum brought about by the combination with all characters correlated with leaf angle.

Acknowledgements We wish to express our gratitude to Professor D. S. Falconer for very valuable suggestions for the revision of this paper and to Dr P. Stam for comments on an earlier draft of the manuscript. The figures were drawn by $\mathrm{H}$. Mulder. These investigations were supported by the Foundation of Fundamental Biological Research (BION), which is subsidised by the Netherlands Organization for the Advancement of Pure Research (ZWO).

\section{REFERENCES}

ANTONOVICS, J. AND PRIMACK, R. B. 1982. Experimental ecological genetics in Plantago VI The demography of seedling. transplants in Plantago lanceolata. J. Ecology, 70, 55-75.

BARBER, H. N., HALSALL, D. M. AND PALMER, J. H. 1968. Genetic, environmental, and physiological control of leaf orientation in Plantago lanceolata. Aust. J. Biol. Sci., 21, 641-648

BØCHER, T. W. 1943. Studies on variation and biology in Plantago lanceolata. L. Dansk Bot. Archiv., 11, 1-18.

BRADSHAW, A. D. 1984. The importance of evolutionary ideas in ecology and vice versa. In Shorrocks, B. (ed.) Evolutionary Ecology, Blackwell, Oxford.

CAVERS, P. B., BASSETT, I. J. AND CROMPTON, C. S. 1980. The biology of Canadian weeds, 47. Plantago lanceolata L. Can. J. Plant Sci., 60, 1269-1282.

C.HARLESWORTH, B. 1984. The evolutionary genetics of life histories. In Shorrocks, B. (ed.) Evolutionary Ecology, Blackwell, Oxford

Cheverud, J. M. 1984. Quantitative genetics and developmental constraints on evolution by selection, J. Theor. Biol., $110,155-171$

DUDLEY, J. W. 1977. 76 generations of selection for oil and protein percentage in maize. In Pollack, E. et al. (eds) Proc. Int. Conf. Quantit, Genetics 1976, lowa State University Press. 
FALCONLR, D. S. 1981. Introduction to Quantitative Genetics, 2nd edn. Longman, New York.

FISHER, R. A. 1930. The Genetical Theory of Natural Selection. Clarendon Press, Oxford.

hegmanN, J. P. AND dingle, H. 1982. Phenotypic and genetic covariance structure in milkweed bug life history traits. In Dingle, H. and Hegmann, J. P. (eds) Evolution and Genetics of Life Histories, Springer, New York.

IIILL, W. G. 1972. Estimation of realised heritabilities from selection experiments. I. Divergent selection. Biometrics, $28,747-765$.

KACSER, H. AND BURNS, J. A. 1981. The molecular basis of dominance. Genetics, 97, 639-666.

LANDE, R. AND ARNOLD, S. J. 1983. The measurement of selection on correlated characters. Evolution, 37, 12101226 .

LAW, R. 1979. Ecological determinants in the evolution of life histories. In Anderson, R. M. et al. (eds) Population Dynamics, Blackwells, London.

LAWRENCE, M. J. 1984. The genetical analysis of ecological traits. In Shorrocks, B. (ed.) Evolutionary Ecology, Blackwell, Oxford.

MITCHELL-OLDS, T. 1986. Quantitative genetics of survival and growth in Impatiens capensis. Evolution, 40, 107-116.

MITCHLLL-OLDS, T. ANID RUTI.EDGE, J. J. 1986. Quantiative genetics in natural plant populations: A review of the theory. Amer. Nat., 127, 379-402.

NIKLAS, K. J. 1988. The role of phyllotactic pattern as a "Developmental constraint" on the interception of light by leaf surfaces. Evolution, 42, 1-16.

PALMIE, J. O. AND DINGIE, H. 1986. Direct and correlated responses to selection among life-history traits in milkweed bugs (Oncopeltus fasciatus). Evolution, 40, 767-777.

SCHAAI., B. A. AND LEVERICH, W. J. 1987 Genetic constraints on plant adaptive evolution. In Loeschcke, V. (ed.) Genetic Constraints on Adaptive Evolution, Springer, Berlin.
SCHLICHTING, C. D. 1986. The evolution of phenotypic plasticity in plants. Ann. Rev. Ecol. Syst., 17, 667-693.

SILANDER, JR. J. A. 1985. The genetic basis of the ecological amplitude of Spartina patens II Variance and correlation analysis. Evolution, 39, 1034-1052.

VAN GROENFNDAEL, J. 1985a. Selection for Different Life Histories in Plantago lanceolata. Ph.D. Thesis, University of Nijmegen.

VAN GROFNENDAEL, J. 1985b. Differences in life histories between two ecotypes of Plantago lanceolata L. In Studies on Plant Demography: A Festschrift for John L. Harper. White, J. (ed.) Academic Press, London.

VAN GROENENDAEL, J. M. M. 1986. Life history characteristics of two ecotypes of Plantago lanceolata L. Acta Bot., 35 , 71-86.

VAN DER TOORN, J. AND TEN HOVF, H. J. 1982. Variability in some leaf characters in Plantago lanceolata. Proc. Kon Akad. v. Wetensch., Afd. Nat. Tweede reeks, 79, 45-51.

VAN DER TOORN, J., TEN IIOVE, II. J. AND VAN F:LDIJK. F. 1984. Transplant experiments with Plantago lanceolata. Proc. Kon. Akad. v. Wetensch., Afd. Nat. Tweede reeks, 82, $39-44$.

WOLFF, K. 1987. Genetic analysis of ecological relevant morphological variability in Plantago lanceolata L. II Localisation and organisation of quantitative trait loci. Theor. Appl. Genet., 73, 903-914.

WOLFF. K. 1988. Natural Selection in Plantago Species: a Genetical Analysis of Ecologically Relevant Morphological Varia. bility. Ph.D. Thesis, University of Groningen.

WOLFF, K. AND VAN DELDEN, W. 1987. Genetic analysis of ecological relevant morphological variability in Plantago lanceolata L. I Population characteristics. Heredity, 58, 183-192. 